\title{
Putting Context to Numbers: A Geotechnical Risk Trajectory to Cost Overrun Extremism
}

\begin{abstract}
The study investigates the cause of the unusually high cost overruns experienced in highway project delivery in the tropical wetland setting of the Niger Delta region of Nigeria. This is in view of the extensive literature supporting the link between geology, the lack of geotechnical best practices and cost overruns. An empirical profiling of cost overrun research further reveals the predominance of mono-method studies based on survey methods, correlative analysis and archival data modelling techniques, all of which are underlain by positivism. The study argues that such positivist philosophies, although methodologically valid, cannot adequately explain and provide in-depth understanding of the contextual cost overrun drivers in highway organisations., Using a robust and thoughtfully designed mix of methods, the paper examines the contribution of geotechnical risks to cost overruns experienced in highway project, and demonstrates the relevance of context in cost overrun research. Cost overrun data from documentary sources for 61 completed highway projects in the Niger Delta are gathered and analysed, revealing an average value of $216 \%$, with extreme cases, ranging up to $1925 \%$ of budgeted cost. To uncover the intrinsic contextual drivers, 16 interviews were conducted with participants from the three highway agencies in the region, responsible for the execution of the sampled highway projects. Adopting a geotechnical narrative, the data is thematically analysed, deductively and inductively. The results of the analysis identified that poor project governance, management and procurement practices, have inhibited the competent management of geotechnical risk, creating a propensity for extreme cost overruns on the highway projects. The study submits the phenomenon of cost overruns in public infrastructure projects is underlain by a complexity of contextual social constructs, which would have been overlooked in positivists studies. Cost overrun research therefore, needs to be contextually and numerically anchored.
\end{abstract}

Keywords: Context, Cost overruns, Highway projects, Mixed methods, Social Constructs

\section{Introduction}

The consequences of cost overruns in highway projects have raised questions about the efficiency of governments and more specificially the organisations tasked with delivering public highway investment to initiate and deliver highway infrastructure projects throughout the developed and developing world. The phenomenon of cost overruns in highway projects has consequently attracted profuse scholarly attention. Including seminal studies such as those undertaken by Wachs (1989) and later Flyvbjerg et al. (2002). As well as numerous recent studies such as those undertaken by Love et al., (2012, 2016, 2017), Ahiagu-Dugbai et al. $(2014,2015,2017)$ and Love $(2015)$ Collectively these studies have once again advocated the need to explore and critique the potential factors giving rise to cost overruns in transportation projects.

The literature reports cost overruns figures of varying degrees in transportation projects located across the globe. With Flyvbjerg et al. (2009) espousing cost overruns ranging up to 50 per cent 
are common, whereas cost overruns above 100 per cent are unusual. Typically, isolated cases of unusually high cost overruns such as those experienced on the Chanel-tunnel in Britain, The Big Dig- A central artery tunnel in Boston and the Edinburgh Trams project in Scotland, have thus constituted detailed case studies in the cost overrun literature (Creedy, 2006; Ahiagu-Dugbai et al., 2014). Highway commissioners on these projects have stereotypically attributed these unusually high cost overruns to project uncertainties including: complexity, scope creep, unforeseen geological conditions and the impacts of conflicting stakeholder pressures. (Flyvbjerg et al., 2009).

In the Niger Delta region of Nigeria, adverse ground conditions have been repeatedly identified by highway agencies as the principle justification for the extreme cost escalations recorded on highway projects, with most, if not all, completed highway projects recording significantly high cost overrun figures. Okon (2009) quoted cost overrun figures as high as $500 \%$ associated with some of the completed highway projects in the region. In 2012, a Presidential Projects Assessment Committee (PPAC) was set up to explore the extent of cost overrun in Highway projects undertaken in the Niger Delta region. The inquiry discovered that between 2005 and 2011, 609 projects were initiated, of which $222(37 \%)$ have been completed, $102(16 \%)$ were on going and 285 (47\%) have been abandoned. The committee's final report was highly critical of the Niger Delta Development Commission (NDDC), the highway agency responsible for the construction of new highway networks in the region from 2001. As part of their scathing analysis, the committee's report highlighted:

"...the unjustifiable introduction of astronomical variations on the contracts sum of most projects over short periods of time, with some of these variations effected prior to project commencement". (PPAC, 2012:13).

Several empirical studies, including those undertaken by Sunjka and Jacob (2013) as well as Ihuah and Benibo (2014) contend unclear definitions of contract terms and poor project administration by the highway agencies, have caused significant cost overruns, delays and abandonment of highway projects. The modalities of contract award and execution by highway agencies in the Nigeria is thus generally criticised in the literature, as being poorly packaged, with contractors standing to benefit from this shortcoming. This view is further reinforced by the World Bank's (2000) Country Procurement Assessment Report (CPAR) for Nigeria, and a recent communique issued at the National Project Cost Reduction Summit (2017). Collectively these pronouncements espouse the need to align best practice into highway project delivery in the region, with calls for setting up highway construction cost information system and database to ensure good governance and accountability. From the extant literature, it is clear academics, professionals and funding organisations are universally critical of the highway infrastructure procurement climate in Nigeria. Espousing this to be fraught with numerous anomalies, which in turn account for extreme cost overruns on projects.

Yet, consistent referrals to lack of geotechnical best practice by the highway agencies have also been cited. Several empirical studies (Mansfield et al., 1994; Okpala and Aniekwu, 1998; Ajibade and Odeyinka, 2006; Ubani and Ononuju, 2013) have identified issues, including: weak and insufficient technical studies and preliminary engineering, design and specification deficiencies as well as inaccurate budgetary and engineering design estimates as contributing to the high spate of prolonged project delays and abandonment, often spanning years, and in extreme cases, decades (NDES, 1997). As such whether competent geotechnical evaluation is undertaken before the commencement of major highway projects in the region remains in doubt.

This is especially significant given the geological nature of the Niger Delta, which as an archetypal tropical delta. Consequently it is crisscrossed by a myriad of streams, rivers and inland water channels (Oguara, 2002). Its terrain consists of varying geological formations, with a significant proportion having difficult expansive clayey sub-soils (Teme, 2002). Logically this implies that any form of construction work in this heterogeneous terrain will invariably 
encounter distinct technical and financial connotations (Oguara, 2002, Youdoewei, 2013, Ngerebara et al., 2014). Considering the peculiar terrain of the Niger Delta, the views of several authors in the literature are convergent in underscoring the need to manage and analyse uncertainties associated with the difficult geology, in the delivery of highway infrastructure projects (Oguara, 2002, Teme, 2002, Youdoewei, 2013, Ngerebara et al., 2014).

As a result of the extensive literature supporting the link between geology, the lack of geotechnical best practices, and cost and time overruns, the study examines the contribution of geotechnical risks to cost overruns experienced in highway project delivery in the Niger Delta. The study in adopting this geotechnical trajectory to investigate the phenomena of extreme cost overruns, however recognizes and does not dispute other potential confounding variables, which may underlie the propensity for highway projects in the region to exceed initial cost figures by such wide margins.

\section{Literature Review}

The cost performance of construction projects is often identified as a fundamental measure of success for project sponsors. Yet against this, a large number of construction projects documented in the public domain, have been censured for notoriously running over their original budget estimate. Cost overrun in construction projects remains a topical issue, with the media, technical press, and scholarly literature, rife with publications analysing cost overrun trends, identifying their primary causes, and offering broader explanations for this pervasive trend. This section reviews the nomenclature of the empirical literature on the problem of cost overruns in construction projects.

\section{Studies Analysing Structured Responses}

An analysis of the literature on cost overruns reveal a predominant leaning towards the use of survey researches, mostly based on analysis of questionnaire surveys which sample the opinions of construction professionals. See for example Mansfield et al., 1994; Chang 2002; Aibinu and Odeyinka, 2006; Kaliba, et al., 2008; Memon et al., 2011. These studies often generate a long list of factors, which are sometimes subsequently ranked. Aibinu and Odeyinka, (2006) identified 44 factors, prioritising the 39 factors on a ranked profile, as a source of useful information for construction industry stakeholders, in curbing delays and cost overruns. Some other authors including Cantarelli et al. (2010); Allahahium and Lui (2011) and Brunes and Lind, (2014) have taken the evidence one step further, by seeking to categorize and classify the myriad of causative variables identified, into a typology of causes, on the grounds that generating a long list of factors, without tracing their fundamental defining characteristics, was insufficient. For example, Allahahium and Liu (2011), analysed 90 causes of cost overruns, identifying five major triggers for cost overruns including: (1) Market volatility principally due to micro and macro-economic variations; (2) novelty/unpredictable events such as unexpected ground conditions; (3) estimate distortion; (4) time pressures and finally (5) project complexity.

The methodology of listing factors, ranking, and categorizing causative variables, based on impersonal questionnaire surveys, which is the most rudimental and simplistic approach to explaining cost overruns, appears to have flooded the literature. Although this adds to the body of scholarly literature on cost overruns, and are methodologically valid, the researchers believe that these forms of empirical analysis cannot be used as a basis for inferring specific causeeffect relationship. With Ahiagu Dugbai et al. (2014:868), describing the bulk of cost overrun research, as replicative, stating:

"It is argued that questionnaires alone may not be suitable for investigating complex and systemic problems like cost overrun on construction projects... It is no surprise that the same factors seem to come top of the list most of the time ...".

This characteristic feature of questionnaire based studies, limits the usefulness of the output of such research, in generating context specific explanations that can be relied on in practice. 
However, a scant number of studies based on questionnaire surveys, are methodologically more robust (Memon and Rahman, 2013; Sharma and Goyal, 2014). These studies have gone a step further to develop explanatory relationships amongst the identified costoverrun factors. For instance, Memon and Rahman (2013) investigated the effect of cost overrun factors based on survey responses of client, contractor, and consultant representative involved in handling small scale projects in Malaysia. A total of 54 survey responses were analysed using the Partial Least Square Structural Equation Modelling, a form of factor analysis, to model the relationship amongst various factors. The outcome of the analysis revealed latent factors which triggered the highest variance: contractor's site management related factors, had the most significant effect on small scale projects. Whereas Sharma and Goyal (2014) developed a fuzzy logic model for assessing cost overrun, based on a preliminary questionnaire survey, conducted to judge the level of importance of the identified factors. This was used in mapping out decision trees on an input and output basis, complemented by graphical representation of the variation induced by different combination of cost overrun factors, to understand their combined effect. Sharma and Goyal (2014) fuzzy model showed that the largest hypothetical variation in cost overrun will be largely due to inadequate planning and scheduling, followed by variation due to short bid preparation time and experience of contractor.

However, a discernible shortcoming of the models, developed by both Memon and Rahman (2013) and Sharma and Goyal (2014), is that the data used in their analysis was not sourced in relation to specific projects or based of any form of project information. These studies relied solely on the general opinions of construction professionals, to infer abstract statistical inferences about the generality of factors that lead to cost overruns. It is thus probable that these models can explain the relationships amongst the cost overrun factors, but may have little explanatory power to account for recorded cost overruns on a project specific basis. This can be rationalised in lieu of the fact that technically projects are unique, which is in stark contrast to the underlying assumptions of the findings of these studies. Furthermore, matters of sensitive dependence arise, in the generalisability of the study by Memon and Rahman (2013) with respect to small scale projects in Malaysia, as the study assumes that projects of a similar size will experience similar issues.

\section{Studies Advancing Spurious Correlations}

In addition to the afore mentioned groups of cost overrun studies, few others provide and analyse cost overrun data, to test specific project variables in accounting for the trend in the data, as explanations for the cost overruns. Typically, Hinze and Gregory (1991), empirically tested for the effects of project size, location and complexity on the level of cost overruns experienced on projects executed by the Washington State Department of Transport. Flyvbjerg et al. $(2002,2004)$, conducted a similar study, from a sample of 254 transportation infrastructure projects drawn from countries in different regions, mostly located in the northern hemisphere. Akoa (2011) conducted a study on highway projects in Cameroun. These studies concluded that the bigger sizes and complexity of infrastructure projects are correspondingly reflected in the increased levels of cost overrun. Hinze and Gregory (1991), further inferred, that the simultaneous nature of projects execution by highway agencies, invariably implied lesser amounts of pre-and post-contract engineering hours available to each, thus accounting for the higher levels of cost overruns often induced in highway projects. Additional engineering, was thus stated as requisite, to overcome risks occasioned by the complex and simultaneous nature of highway project execution, which often creates a propensity for such projects to run over budget. Whereas, Flyvbjerg et al. (2004), asserted that the average length of implementation phase of transportation projects significantly impacted on the level of cost overruns recorded. This was inferred based on an analysis of cost overruns experienced on bridges, tunnels, and roads, which showed that cost overruns varied in relation to project duration. Bridges and tunnels, with average duration of 6.6 years recorded higher cost overruns than rail and road projects with an average duration of 6.3 and 4.3 years. Flyvbjerg et al. (2004:15) thus concluded, sluggish planning and implementation of transportation projects had direct financial repercussions, stating: "Sluggishness may, quite simply, be extremely expensive". 
However, other studies, such as those by Odeck (2004) in Norway, revealed that larger cost overruns were experienced on smaller projects. Morris (1990) also arrived at a similar conclusion for 290 Indian projects analysed. Yet, contrary to the findings of these studies, Love et al. (2013) revealed that cost overruns do not vary by project type or size. The conflicting results, from various studies, further reinforces the discernible shortcoming of these studies, that conclusive inference is mostly drawn based on exploratory statistical analysis. Typically, the use of correlation analysis, which by virtue of reporting significant association between bivariate groups of variables, cannot be used to conclusively infer causality. These studies thus assume that the dependent variable (Cost overrun) changes solely because of the independent variables (project size, project type and complexity). Citing the popularly used phrase in statistics: 'Correlation does not necessarily imply causation'.

\section{Studies Analysing Causation Based on Project Data}

Quantitative analytical techniques, which analyse cause-effect relationships, are generally grouped as mathematical models (An et al., 2007). Models are reductions of reality replicating an intricate system using variables within those systems (Ahiagu Dugbai, et al., 2014). Mathematical models have however been scantly used in the literature to infer causality in relation to project cost overruns. The techniques which have being used to analyse cost overrun in a limited number of older and more contemporary studies include: Linear modelling techniques such as regression modelling, networking and data mining techniques such as artificial neural networks, heuristics based models such as case based reasoning, stochastic techniques such as monte-carlo simulations; and logic based methods such as binary logistic modelling and fuzzy logic (Love, 2002; Trost and Oberlender, 2003; Attala and Hegazy, 2003; Ahiagu Dugbai et al., 2014; Lee and Kim, 2015 and El-Kholy, 2015)

Typically, older studies such as Trost and Oberlender (2003) as well as Attala and Hegazy (2003) have used linear modelling techniques, based on regression analysis, to analyse cause-effect relationships in explaining recorded cost overruns in projects, and further tested the validity of these models with respect to their use in decision making for future projects, at specified levels of confidence. A more recent study by El-Kholy (2015) generated a regression based model, while comparing its predictive capacity to a Case Based Reasoning (CBR) model for similar data sets derived from 30 projects. The outcome of the study showed that the regression modelling had higher levels of accuracy to predict potential cost overrun in projects. El-Kholy (2015) further applied a CBR model to predict the likely cost overrun given the degree of similarity of the project characteristics. El-Kholy (2015) used this method to analyse cost overrun factors, whose presence as part of a future project, is indicative of a potential to result in a similar degree of cost overrun, useful in reference class forecasting and decision making for future projects. Ahiagu Dugbai et al. (2014) used data mining techniques based on artificial neural networks, to analyse the complexity of non-linear interactions amongst quantitative project variables such as compensation events, project duration, as well as qualitative information on tendering method, location, project type, fluctuation measure and project's delivery partner. Lee and Kim (2015) used monte-carlo simulations to analyse the statistical distribution of change orders issued during the construction period, which lead to significant cost overruns. Love et al. (2013) developed a probabilistic log-logistic distribution of cost overruns for 49 road projects (new roads including upgrades and elevated highways) in relation to rework occasioned by errors and omissions in contract documentation, leading to cost overruns.

Although this class of technical studies on cost overruns which rely on modelling to understand cause-effect relationship, have a robust and methodologically valid underpinning, rooted in the specifics of project data, with a direct applicability useful in monitoring and reassessing future projects, there is a discernible lack of context.

\section{Geotechnical Practises as Contextual Cost-Overrun Drivers in Highway Projects}

Ground conditions have been repeatedly asserted to account for a huge percentage of the technical risk posed to highway development, due to its complex interfaces with the design and construction of transportation projects (ICE, 2001). As numerous case histories have shown, failure to anticipate ground conditions can have severe financial implications for projects (NEDO, 1988; DETR, 2014). It is thus a requirement of best practice that a well-structured 
application of risk management in general and geotechnical risk management in particular, is fundamental to avert cost overruns in transportation infrastructure (Staveren. and Meer, 2007).

It has however been argued that variations due to unexpected site or soil conditions may be unavoidable. (National Economic Development Office, 1988). With Wong (2010) categorising contractual risks due to ground conditions as 'foreseeable', 'unforeseen', and 'unforeseeable'. The distinction being that foreseeable ground risks are those that can be reasonably anticipated, while unforeseen risks are those that were unanticipated due to incompleteness or short comings in the investigations. Unforeseeable risks on the other hand, were defined as those risks that cannot be eliminated, and are therefore beyond the contractors control, regardless of the level of experience on his part or how much ground investigation is undertaken. This implies that although competent geotechnical risk management may not completely eliminate risks due to the ground, it can to a great extent, minimise it.

This brings to the fore, the human factor in geotechnical risk management. As empirical studies by Bea (2006) and Sowers (1993) reveal, differences in risk perceptions, awareness and knowledge may contribute to poor geotechnical risk management. Documentary analysis of 600 projects showed that $80 \%$ of post contract issues were triggered by non-technical factors, such as organizational and knowledge uncertainties. This outcome aligns with findings by Sowers (1993), who reported that $88 \%$ out of 500 project failures were caused by human shortcomings, while technological shortcomings accounted for the remaining $12 \%$. With Brandt (2004) asserting "There are no insurmountable weak soils or rock, there are only weak engineers".

Potential shortcomings in organizational practice thus represent an additional layer of avoidable financial risk, compounding the inherently unforeseeable elements of ground risks. This has led to arguments in the wider cost overrun literature that consistent referrals to unexpected geologic features as accounting for cost overruns in transportation projects, may be systematic and not erroneous, in view of the advancement in risk analysis and tools for managing risks (Flyvbjerg et al., 2002, 2004, 2009). Such deviations from geotechnical best practice within highway agencies, which would have implications for the accuracy of projected cost estimates, and logically constitute cost overrun drivers contextual to highway organizations, are thus reviewed.

\section{Geotechnical Trajectories to Cost Overruns}

Accuracy in cost estimating under conditions of uncertainty is typical of most construction projects. For road works, the level of accuracy of cost forecasts made is determined by the contributory cost variables that are captured in that estimate (Chou, 2005). Therefore, the limit to which cost overruns can be averted is bounded by the risk factors accounted for in projected estimates (Turouchy et al, 2011). Such typical limiting factor is ground conditions. With routing of highways characteristically being predicated on the outcome of ground investigations, necessary to avoid particularly difficult subsoils, to achieve value for money (ICE, 2001).

Adequately defining ground conditions at increasing levels has been advocated as a fundamental measure of geotechnical risk management, necessary to ensure higher levels of accuracy in projected cost figures (Reiley et al., 1994; Evans and Peck, 2009; Romero and Stolz, 2009). The literature in this section thus X-rays the various routes through which mismanaged geotechnical risks can potentially trigger cost overruns, from the conceptual and detailed estimate phase of cost estimation, to the tendering/contractual phase of highway project procurement.

At the conceptual phase, Turouchy et al. (2001) reports that, earthworks/pavement cost, with the associated preliminary engineering, represented the most difficult cost item to estimate at the conceptual phase of highway project development, and often accounted for the largest deviations from final cost. Based on a survey of 32 highway agencies, Chou (2005) reported that during budget projections, most highway agencies deployed estimating methods, based on cost per-mile tables, with adjustment made for project specific incidentals, using informal engineering judgment, resulting in highly inaccurate forecasts as potential variations in ground profile are not captured. Chou (2005) thus opined that the prevalence of such practices, despite 
the wide variety of quantitative analytical techniques, may be due to the speed and ease of their applicability, low risk perception or lack of skills to use more advanced conceptual estimation techniques. In contrast, Turouchy et al. (2001) reported that the few highway agencies which dedicate a relatively large amount of financial and human resources to preliminary engineering, and had very low deviations from their initial cost estimates. This supports the viewpoint of Romero and Stolz (2009) that for transportation projects which have a high level of interface with the ground, the use of 'off-the-shelve historical data in budgeting was not adequate, resulting in estimates which are no more than just guestimates. With, Flyvbjerg et al., (2002) arguing: "ignoring or underplaying geological risk may be helpful in getting projects approved, but no other risk factor is more likely to boomerang back and haunt projects during construction" (p. 281).

Furthermore, an inadequately costed contract, with the contract price built up based on incomplete details of the ground or incorrect assumptions represents a medium whereby geotechnical risk may not be captured. Typically, in terms of pavement cost, inadequate ground investigations may lead to inappropriate pavement designs causing underestimation of material costs, as the combined thickness and material specification of the structural layers, from subgrade to surfacing, will vary per soil type (TRRL, 1993). Failure to adequately evaluate the geotechnical properties of the highway route may also result in increased costs for bridge/culvert construction, drainage works, and scour protection. Comprehensive geotechnical investigation is equally a precursor to the selection of appropriate methods of construction, and as such can lead to the underestimation of method and time related charges in the computation of detailed estimates. Adequate geotechnical evaluation is thus fundamental to managing ground in the preparation of project estimates ultimately shaping the cost profile of the financial inputs of material, labour and equipment necessary for the construction of highways.

At the procurement phase of highway projects, the dynamics of geotechnical risk aversion and the strategic behavior of clients and contractors also has important implications for the accuracy of project final outturn cost. As Moleenar et al. (2006:31) reiterates: "The contract is a vehicle for risk allocation ... it defines the roles and responsibilities for risks... contractual misallocation of risk has been found to be a leading cause of construction disputes and overruns". Providing geotechnical investigations reports as part of contract documentation can be identified as a form of geotechnical risk containment. A note of caution is, however, sounded by O' Toole (2006), who raises valid concerns about the accuracy and representativeness of such ground investigation reports, suggesting that where incomplete or inaccurate reports are used as a basis of financial and risk assessments by contractors, the client faces significant financial risk due to contractual change events resulting from report inaccuracies. As a result, case law related to construction projects, is rife with cases where the core argument revolves around the issue of non-representative ground investigation reports.

Best practice thus advocates for resort to the use of Differing Site Condition clauses in contracts, which would mean paying for those conditions that could not have been revealed in detailed investigations. However, some forms of contracts resort to including 'Site Inspection Clauses' stipulating that contractors carry out all requisite inspections, are thus liable for unexpected conditions of the ground. The preceding arguments indicate a divergence between practices, as some highway agencies tow the latter, and try to transfer the risk associated with the ground conditions to contractors in their misguided notion of ensuring certainty of final outturn cost (Harrison, 1981; Geddes, 1985; Chan and Au, 2007). Such practices lead to inadequate containment of geotechnical risks due to potentially undetected ground conditions, with contractors having to rely on guesswork to project estimates, which are forwarded in bids.

This may be further compounded whereby clients opt to award contracts on a lowest bidder basis, at the risk of contractor's incompetence (Crowley and Hancher, 1995). Such practice contravenes best practice, which emphasizes the need for an informed unbiased appraisal of contractors' technical capabilities relative to bid price using quantitative multiparameter models (Gransberg and Gad, 2014). Such comprehensive approaches to contractor selection require the assignment of relative weighting of critical geotechnical factors, 
aggregated in deciding on the winning bid. Minimal geotechnical requirements relative to other factors may thus be necessitated under routine construction work in better ground conditions, with higher requirements in more complex projects or in adverse difficult ground conditions. Remarking on the preceding scenario, as a financial gamble by clients, Chan and $\mathrm{Au}$ (2007:3) opined that: "The owner risks tragedy, first, from cost-cutting measures the contractor will take if it hits unforeseen conditions, and then, from fighting contractor claims and picking up the pieces if the contractor abandons the project or goes bankrupt".

The lack of comprehensive and accurate geotechnical investigations; the nature of costing methodology deployed- which determines the quality of estimates relied on, as well as a lack of well-articulated geo-risk allocation and contractor selection measure by highway agencies in the procurement of projects, may compromise the efficient management of geotechnical risks. Table 1, summarises the various potential pitfalls in organisational practise which may trigger underestimation of geotechnical risks.

Insert Table 1 here

The outlined geotechnical trajectories thus constitute contextual barriers in the practices of highway organisations that can potentially lead to variations, costly disputes and delays, invariably affecting the ability of highway projects to be completed under budgeted cost.

\section{Research Methodology}

The empirical profiling of cost overrun research has revealed the predominance of monomethod studies based on questionnaire survey methods, correlative analysis and archival data modelling techniques, all of which are underlain by positivism, which relies on the reduction of ideas into discrete numeric measures of observation (Cresswell, 2003). The artificial and intensively structured nature of positivist approaches cannot capture the characteristic features in organizations, such as how the hierarchy of authority impacts on practice. The implication being that facts which can only be relayed via the richness of data from descriptive narratives, will be missed out. As Dainty (2008:7) posits: "An enduring adherence to the positivist paradigm will do little to enable construction management researchers to grasp the meaning of social action from the perspective of the actors involved". Love et al. (2012) were of similar view, observing that providing details useful to provide a history to projects, is mostly lacking in cost overrun research. With Ahiagu-Dugbai et al. (2014), arguing that there needs to be more useful and robust research, targeted at understanding the propagation of cost overruns. The lack of context evident in the predominant leaning to numbers, thus constitutes the argument in this study.

In response to the gap identified in the literature, this study is structured, as a distinctive and significantly robust departure from previous empirical studies on cost overruns. The researchers use a multi-method analysis to convergently provide context specific explanation to the prevailing trend of significantly high cost overruns experienced on Niger Delta's highway projects, using a geotechnical narrative.

\section{Research Design}

The case study research strategy is used to study the phenomena of unusually high cost overruns reported on Niger Delta's highway projects. As Yin (2014) underscores, the most outstanding characteristic of a 'case' must be its significance, which is exemplified by the extreme cost overruns experienced, and the peculiar nature of the Niger Delta's terrain. The technical distinctiveness of the case of Niger Delta's highway projects, thus lends it practical significance in cost overrun research. This theoretical perspective therefore guided all aspects of the design of the case study, as depicted in Figure 1.

Insert Figure 1 here

The unit of analysis, towards which all data collection effort was targeted, was 'Highway 
projects in the geologic setting of the Niger Delta', with embedded units as shown in Figure 1. This study adopts a critical realist philosophical orientation as lenses suitable to understand the phenomenon of extreme cost overruns in Niger Delta's highway projects. Critical realism per Miles and Huberman (1994) calls for both deductive and inductive reasoning to establish causal connections in credible ways, by providing descriptive accounts as evidence to back up the plausibility of such explanation.

Following the preceding line of logic, and in tune with the critical realist philosophical underpinning of this research, theory on Embedded Unit of Analysis 1 (Linking ground conditions to cost overruns) is generated deductively via quantitative analysis, while theory on Embedded Unit of Analysis 2 (linking geotechnical practices to cost overruns) is generated inductively/deductively from qualitative data. The methodological pluralism implied by this mix of data types (Numerical and textual) represents a shift away from the conventional positivist viewpoint of most cost overrun research. As Dainty (2008) recommends, a paradigm shift in the ideology of construction industry research, should materialise in an increase in the use of qualitative methods beyond the predominance of quantitative empiricism evident in most scholarly text.

\section{Data Collection and Analytical Technique}

Cost and locational data from a total of 315 Infrastructure projects (buildings, canalisation, shore protection, and road projects) awarded from 2002 till date, were obtained from the available archival records of the three highway agencies responsible for highway development in the Niger Delta region, represented as HA1. HA2 and HA3. One hundred and Forty-eight of these infrastructure projects were road projects executed at various locations in the Niger Delta (Rivers and Bayelsa States), 61 of which were completed, while 87 were a mix of currently ongoing, delayed and abandoned projects. The project data was filtered down based on the study scope to only road projects. Furthermore, only the completed road projects were analysed, for their levels of cost overruns. No other form of selective sampling was adopted.

This data analysis begins by describing the difficult heterogeneous geologic configuration of the Niger Delta region, and statistically explores this geotechnical undertone as a potential trigger which creates a propensity for cost overruns in highway projects. To this end, content analysis of documentary data for the 61 projects sampled was carried out. This was complimented by a literature survey of geo-spatial studies on the geology of the Niger Delta, available from the extensive work already carried out on local soils. Exploratory statistical test of significant difference was used to analyse recorded cost overrun data for 61 completed highway projects, with goal of establishing spatial association, between the geologic setting of the Niger Delta and cost overrun trends evident in the highway projects.

Further to this, 16 interview were conducted with participants on the design and costing processes adopted by the highway agencies, during the procurement of the highway projects. Ten of the interviews were carried out with the technical professionals, within the highway agencies that commissioned the projects (HA1, HA2 and HA3). The information provided from these interviews, was further complimented by information elicited from six interviews conducted with external registered consultants and contractors, employed by the three highway agencies, to gather additional data related post contractual issues and cross-validate the information provided by the highway officials.

A semi-structured interview format was used to draft the questions in the interview guide used, based on its flexibility and usefulness with respect to providing answers to the research questions. As such depending on the on the flow of interview conversation, certain questions were asked which were omitted in others. Additional questions, not originally part of the interview protocol, were also introduced to probe unanticipated issues that occurred during the interview, and which the researcher considered crucial to the study. As Bryman (1989:26) reiterates:

"The research process often starts with a set of loose concepts, ideas and relationships between issues perceived as relevant and important in relation to the 
knowledge domain based on the investigators preoccupation ... with theoretical reflections filling in the gaps during data collection".

The collated qualitative data was analysed deductively and inductively, using the NVIVO-10, qualitative data analysis software, after transcribing the taped interview conversation. The analysis commenced using a principally deductive approach, following a theoretical framework derived from the literature on geotechnical best practice. The first phase of analyses of the interview data therefore, was structured along established standards of geotechnical best practice, in line with the suggestion of Yin (2003: 56):

"Since established theory is often the basis for formulation of initial research questions and objectives, the same theoretical perspectives can be deployed to direct the research reasoning of the study".

However, the $2^{\text {nd }}$ phase of the qualitative data analysis was inductive, as the researchers sought to identify un-anticipated themes emerging from the data. The interview transcripts were thus re-read to match patterns repeatedly occurring across the data. The analysis in this regard was carried out without following a structured theoretical framework, similar to grounded theorizing. Table 2 is an outline of the logical stages of qualitative analysis deployed in the study for data reduction, display and inference drawing, following the recommendation of Miles and Huberman's (1994).

Insert Table 2 here

As Table 2 shows, two stages of cluster analysis were carried to bring the number of codes down, and to a more hierarchically structured network, more specific to the objectives of the study: Clustering of interrelated micro-codes into more distinct subthemes; and clustering of sub themes into parent nodes. Some of the less distinct micro themes, which less repeatedly occurred were thus merged into each other, before clusters of parent themes were derived.

Verification was further carried using an intra-case analysis of the similarity and contrast of responses elicited from the different groups of respondents interviewed from the three highway agencies. This is because unlike quantitative research which primarily seeks to address issues of reliability and validity, qualitative research emphasizes the relevance of social conditioning to the reasoning process and its role in our understanding of a phenomena. Raoke and Kaguoglo (2007) thus recommend that qualitative data and output should be justified and validated using some other supplementary methods following the three fundamental tenets of qualitative research. This include: the Postulate of Subjective Interpretation which requires studying social phenomena from the simultaneous perceptions/viewpoints of the actors; Postulate of Adequacy, which requires that explanations of human actions should be credible i.e. reasonable and understandable; and the Postulate of Logical Consistency which requires that the information being gathered and studied is consistent with the purpose of the study, and relevant to the adequately operationalize the concepts being studied.

The Intra-case analysis thus served as a measure necessary satisfy the Postulate of subjective interpretation. As Bryman (1989) further points out, cross-verification of data used for drawing inference in qualitative organizational studies is necessary due to potential issues such as:

Whether it is possible for a single informant to provide accurate information on the organization as a whole?

The possibility of variability of status of the informant affecting the reliability of information provided, which may have implications for the comparability of data.

- The potential for error, ignorance bias or deliberate distortion of facts from a single informant.

Using such approach, the researchers were able to match repeatedly occurring patterns, which also facilitated the development of reasonably coherent explanations, further satisfying 
the Postulate of Adequacy. The incorporation and triangulation of data from multiple sources further strengthened the adequacy of the inferences made, ensuring that premature conclusions were not drawn from circumstantial evidence (Miles and Huberman's 1994; Raoke and Kaguoglo, 2007). The requirement of the Postulate of Logical Consistency necessary to adequately operationalise the study concepts, were satisfied via: the explicit definition of concept, case and context being studied; Identification of units of analysis, and acquiring data to measure them; and increasingly establishing the chain of evidence from the exploratory statistical analysis of archival data to the descriptive qualitative analysis of interview data. Furthermore, using a theoretical framework derived from the literature on geotechnical best practice as a proposition to guide data analysis, enhanced the analytical generalisability of the findings beyond the specific context of the study area. Other measures carried out, necessary to ensure the credibility of study's contribution to knowledge included the preparation of predesigned interview templates, ethical consent and introduction letters to the study participants as part of the case study protocol, as well as outlining in detail the specifics of data collection methods and analysis.

\section{Data Analysis and Results}

\section{Exploratory Data Analysis: Linking Ground Conditions to Cost Overruns}

The general geology of the Niger Delta consists of various types of sub soils. Sub-soils in the riverine areas of the Niger Delta, predominantly consists of extremely soft deltaic marine clay locally referred to as 'Chikoko', with very low bearing pressure (Otoko and Pedro, 2014). This relative to the uplands which have firmer subsoils. The implication of this extreme geologic variation is its influence on earth works, the nature of pavement design, volume of construction materials needed, and the methods and process of construction. Typically, in terms of earthworks, the problematic marine clays/peat (Chikoko) soils, rated as very poor, with its characteristic shrinkage and swelling potential, abound to varying degrees in the geo-zones. The remedial re-engineering measures, as noted by several authors including Oguara (2002), Youdoewei and Nwankwala (2013) and Otoko (2014) could imply additional costs of earth works for:

- Excavation and replacement of poor soils to the extent of prevalence, i.e. volume of cutto-fill/cut-to-spoil, volume of fill materials, compaction costs and the accompanying method and time related charges.

- Preloading with free draining material;

- Stabilisation in place with chemical additives to achieve the required minimum strength characteristic for the sub-grade.

Typically, the first alternative will basically entail importing good quality laterites from burrow pits located in more stable terrain to replace the poor soils in marshy areas. Cost of soil replacement will thus be subject to the haulage distance from source sheds, which are often situated in the coastal plain soils of the upper delta, transported via waterways, at considerable costs to construction sites in the swamps and along the coast.

Against the backdrop of the preceding logic, cost overrun data on 61 completed road projects executed at various locations in the Niger Delta, was descriptively analysed revealing values which ranged up to $1925 \%$ over initial estimates. The mean cost overrun value of $216.47 \%$, shows the unusually high cost overrun levels recorded on the sampled highway projects, which at a $95 \%$ confidence level, will likely still fall between $130 \%$ to $303 \%$. The lower limit of this range of cost overruns is still remarkably high compared to the levels of cost overruns evident for highway projects reported in the literature. The dispersion of the data set was however not evenly distributed, but heavily skewed (3.65) with cost overrun values predominantly clustering around values much lower than the mean (Figure 2).

Insert Figure 2 here 
The box plot in Figure 2, shows statistical outliers and extreme values. The skewness of the data thus may be due to the very conspicuous outliers noted, in order of increasing magnitude for project No: $3 ; 48 ; 43 ; 37 ; 52$ and 49 , which has dragged the mean value to be much higher than the median. It is however worthy of note that 5 out of the 6 outliers occur for projects executed in swampy and coastal areas (represented by Zone 2 and 3 in Figure 3). Figure 3 is a geo-spatial delineation of the Niger Delta terrain, which shows various upland, swampy and coastal locations as classified by Teme (2002) whereby: Zone 1-Upland; Zone 2- Swamp; and Zone 3Coastal.

Insert Figure 3 here

Following Teme (2002) geo-spatial delineation, it noted that there is a wide variability in cost overruns values of $1925 \%$ between the minimum of 0.00 occurring in an upland location (Zone 1), and the maximum of $1925 \%$ occurring in a swampy location. To test if cost overruns recorded at various locations vary as their geo-zonation, the cost overrun data was grouped following this geo-demarcation and reported in Table 3 . Table 3 shows significantly differing levels of mean cost overrun recorded in the different geo-zones, which is further corroborated by the outcome an ANOVA test (Table 4), run concurrently after a log-transformation to normalise the data set.

Insert Table 3 here

Insert Table 4 here

As graphically represented in Figure 4, projects located in Zone-2 (swamps) display much higher level of cost overrun.

Insert Figure 4 here

Since relevant engineering parameters, which can only be revealed via adequate geotechnical evaluation, are used to assess the suitability of the varying subsoils as bearing media prior to construction works, the differing levels of financial risk associated with the heterogeneity of the Niger Delta terrain can be provisionally inferred as the factors which are latent in the geologic setting, and which have not been adequately catered for in the projection of cost figures, triggering the cost overrun deferential between these zones. This inference is however subject to the assumption that the final cost of the highway projects reflects all the relevant costs necessary to deliver standardized products at their various geolocations. This is due to the lack of useful benchmark data with which to assess the value for money to the client.

The statistical outcome however indicates an association, and not necessarily causation. It thus does not rule out the possibility of other potential confounding influences typically project complexity, but rather serves as a platform for further in-depth investigation. It was thus the researcher's interim proposition at this phase of the study that: The observed trend in the project data is linked to mismanaged ground related risks, which ideally ought to be clearly defined and tackled, but were not resolved early on at the pre-tender stage, thereby allowed to spill into the contractual and construction phase, leading to significantly differing levels of cost overruns in the geo-zones. Identifying the geotechnical shortcomings/deviations from the dictates of best practice, was thus considered the necessary starting point for subsequent indepth qualitative analysis. 


\section{Deductive Interview Analysis: Linking Geotechnical Practices to Cost Overruns}

The deductive analysis followed the arguments in the literature, depicted as theoretical framework shown in Figure 5, which represents a linear conceptualisation of adherence to standards of geotechnical best practice in the project phases, and the anticipated cumulative impact.

Insert Figure 5 here

All respondents interviewed in the highway agencies, explained that the approach to project development by their respective agencies, was determined by the class/size of the road project. The project development processes were described as varying per the size of projects: Major or community road projects. Major roads were described as inter-city roads, highways and bridges, while community roads were the most common types of roads constructed as streets in urban and rural areas. It was explained that all major projects were procured via the use of external consultants, who handled the design preparation, while community projects were procured inhouse, with detailed preliminary engineering not necessarily undertaken. Figure 6 is an extract of responses, from the interview participants to this effect.

Insert Figure 6 here

Community projects were further described as having no definite pre-contract procedure, being largely determined by the urgency induced by community pressures from youths who have taken up and armed struggle, due to the existing acute infrastructure backlog. Based on the participant responses and the analysed documentary evidence, the level of adherence to geotechnical best practise during the execution of the 61 projects (19 major and 42 community projects) was thus elicited and summarised (Table 5).

Insert Table 5 here

As Table 5 shows, for major projects procured byHA1 and HA2, the researchers had doubts about the adequacy of geotechnical investigations carried out prior to project execution, due to, contradictory responses obtained from participants. Typical response to this effect were:

"...Sometimes geotechnical investigation reports and design drawings are photocopied from other similar previously executed projects and modified".

"Geotechnical professionals prepare detailed soil investigation reports for major projects"

Further analysis of emergent geotechnical themes (Table 6) revealed barriers contextual to the highway organisations, which act to facilitate poor geotechnical practises.

Insert Table 6 here

For major projects, the researcher noted a lack of continuity in the services of external consultants, who were responsible for ensuring geotechnical input at the design phase. This was inferred from the respondents' explanations that consultants who designed major projects at the budgeting phase concluded all design preparation and their services were terminated:

"... the consultants used at the post contract phase are usually different from the pre-contract team, as designs and costing for major projects may be prepared years in advance of the contract award".

It was noted that community projects mostly have no geotechnical professional evaluation throughout the phases, with resort made to crude improvisation to adjudge the nature of soils at project locations. In addition, the organisational structures for two out of the three highway agencies, revealed that no in-house geotechnical professionals were employed by either agency, with the responsibility for geotechnical input in the design of community highway projects. It 
was also inferred that, that no clear-cut definition of professional roles existed within the highway organisations. Consequently, most professionals serve in multiple capacities. For example, the researcher discovered from the responses that quantity surveyors often function as civil engineers. A supposition confirmed by a quantity surveyor employed by HA1 who conformed:

“...I am a quantity surveyor, working under the department of ***, I can perform the job of an engineer and often go to site and based on the survey drawings, prepare schematic drawings for the road project before I estimate the cost.

In HA2, a similar response was noted:

"...I am a quantity surveyor but most times, I serve in the dual capacity of both an engineer and a quantity surveyor: I learnt how to prepare highway designs...”.

It was further revealed that the agencies lacked qualified technical manpower with the requisite qualifications, as a result they were badly under staffed:

“...The quantity surveyors and civil engineers all supervise projects, along with the electrical and mechanical engineers who are attached to them because we are badly short staffed".

"...We have a situation, whereby hundreds of projects being executed by the agency, and running concurrently, are managed and supervised by less than 10 persons. Most of the so-called engineers are not experienced and don't even have adequate qualifications".

There were also instances of job descriptions not matching the qualifications of staff working on road projects. It was discovered that completely unrelated (non-construction) professionals were working in the capacity of project managers and supervisors. This was captured in the very revealing statement from the management staff of the agency in which it was admitted:

"... We have cases of medical doctors, accountants, marine engineers and even petroleum engineers, heading departments in charge of road projects, and working as project managers: supervising projects and approving remittance of payment to contractors.

From the outcome of the deductive interview data analysis an array of factors, relative to standards of geotechnical practice, was thus identified as contributing to the unusually high levels of cost overruns in the highway projects, summarily presented in Table 7.

Insert Table 7 here

\section{Inductive Interview Analysis}

The Inductive phase of the data analysis, sought to highlight recurring patterns across the data. The response pattern revealed a lack of control gateways in project development phases. The responses revealed that projects had no definite procedure for approval, with budget estimates mostly prepared using approximate quantities. Typical responses are captured in Figure 7.

Insert Figure 7 here

Further inductive analysis of the interview data, highlighted the dominant role of people, and external factors particularly from political interference and community pressures, inherent in the institutional system, as impacting on the level of cost overruns recorded on projects. Eight out of the ten participants interviewed from the highway agencies commented on the impact of these on their professional roles. Typical participant responses to this effect are shown in the interview extract (Figure 8). 
Insert Figure 8

Table 8 is an array of socio-culturally constructed forces as induced, which constitute the contextual drivers in the highway organizations actively triggering geotechnical error traps, and have trickled down to result in the unusually high levels of cost overruns experienced in highway projects in the Niger Delta.

Insert Table 8 here

\section{Discussion of Finding}

The observations inferred from the preliminary statistical analysis served to reinforce the researcher's predisposition that the heterogenous wetland conditions of the Niger Delta are linked to the extreme cost overruns experienced on Niger Delta's highway projects. The findings from the statistical analysis at face value appear to corroborate the assertions of the highway agencies, that the region's geology is the primary factor underlying the trend in cost overruns. However, the findings were only exploratory and not conclusive. necessitating further qualitative analysis to uncover what practise based issues within the highway agencies, are responsible for triggering the excessive level of cost overruns on the projects.

The findings from the deductive phase of the interview demonstrates the link between poor geotechnical practises and cost overruns reinforcing the study's presopposition that a lack of adequate geotechnical risk management is fundamental to the extreme cost overruns recorded on Niger Delta's highway projects. Typically, noted was the practice of using non-differentiated costing platforms in budgetary provision for proposed highway projects at the preliminary phases of highway development, despite the heterogeneous sub-soil profile of the Niger Delta region. The findings also showed that there is a predominant lack of rigorous ground explorations, needed for the preparation of adequate and comprehensive designs for highway projects. This is compounded by a lack of adequate geotechnical risk containment measures-via GIR and DSC clauses, in contracts awarded by the highway agencies This is amidst the primarily subjectively and politically driven mode of contractor selection, which is not based on any form of geotechnical criteria, requisite to ensure efficiency of project execution.

Particularly the lack of detailed preliminary engineering has considerable implications for the certainty of project outturn costs- which is further amplified, as the diagnosis of problematic expansive soil types typical of the wetland condition of the Niger Delta, at the precontract phase is necessary if the project team are to address relevant risk and competently estimate costs. This raises the question of value for money to the client, as the project delivered may not necessarily be a standard one, logically linked to the rather robust body of literature centred on investigating the high incidence of premature road failure in the region (Abam, 2005; Aigbedion, 2007; Emujakporue, 2012).

This places a limitation on the preceding analysis, as to conclusively establish causeeffect relation between ground conditions and cost overruns would ultimately require some form of benchmark figure per kilometre of standard highway sizes related to particular classifications of ground conditions, which with the practices uncovered, is not possible. Therefore, a technically competent evaluation of the highway projects is a precursor to further quantitative investigation into the more immediate and project, specific causes.

Further inductive analysis uncovers a link between project governance and project management and cost overruns, highlighting the role of organization and people related variables within socio-cultural settings, as complimentary cost overrun drivers in highway projects. These in turn represent an additional layer of risk contextual to the system of project delivery in the Niger Delta. Typically, these include the: 
- Poorly Constituted Organizational Environment in the various highway agencies, which has served to actively create geotechnical error traps in highway projects;

- Knowledge and Skills Gap evident in the general pattern of the responses. The participant responses showed that most of the in-house professionals, were significantly uninformed about current issues in their profession, which clearly had a significant bearing on their ability to follow the underlying logic behind the line of questioning. This evident gap in the knowledge of the highway officials, can thus be said to be the blue prints, which fosters dysfunctional professional practices, that actively facilitates error traps in highway projects.

- External Socio-Cultural Pressures which has impacted on the professional obligation of project actors. Particularly the impact of political and community interference on in-house professional roles during the procurement of projects is particularly noted by the researcher as being a 'blanket' influence in the Niger Delta, overwhelming all other considerations in the procurement of highway projects. This was evident in the data, which showed the numerous multiplier impacts that external pressure from political and community sources, has had in constraining, the discharge of professional obligations.

- Psychological Barriers, which are put up by the professional actors in highway projects, in response to their level of risk perception of geotechnical issues as well as due to social conditioning inherent in the institutional setting of the highway organisations.

- Dichotomous Project Management Practices indicative of unbalanced management of geotechnical risk, which is a recipe that would logically culminate in significant cost overruns.

- Unethical Practices noted as thriving within the highway agencies, which may be associated with the pre/post contract management of highway projects executed in the Niger Delta. The researcher, however, cannot generalize the prevalence of such un-ethical practices to all project actors in the professional service of the highway agencies. Yet, based on the responses from the highway agencies' staff, the researcher has, however, discovered the existence of internal organizational loopholes, which create a viable ground for such unethical practices, where they do occur, to thrive.

Triangulation of the findings from the study analysis show that the problem of cost overruns in the Niger Delta is multi-layered and multi-dimensional, underlain by a web of interconnected contextual drivers. As Figure 9 depicts, there are major contextual governance faults and knowledge deficiencies in the system of highway project delivery in the Niger Delta which has trickled down to trigger excessive cost overruns.

Insert Figure 9 here

As observed from the data, there are project governance and project management dysfunctionalities, which requires a major culture shift and transformation framework in the highway project environment to allow for proper risk management and procurement processes. Overcoming the predominantly poor geotechnical risk management practices evident in highway organizations requires adherence to best practices by suitably technically skilled staff. This however can only be possible whereby the organizational environment is made conducive, corroborating the viewpoints of Sowers (1993) and Beau (2006) that the human factor in geotechnical risk management is fundamental to the project failures and successes. As a result, the link between ground conditions and cost overruns cannot easily be isolated and understood unless the other overwhelming influences are functioning properly. 


\section{Conclusion}

The study has provided a descriptive snapshot of the practices of the highway agencies in the Niger Delta, which shows that the reality of the situation of project delivery in the region, depicts a far departure from the theory of good practice. The study provides empirical evidence which reinforces the general view that the system of highway project delivery in the Niger Delta is fraught with numerous anomalies. This has impacted on the level of geotechnical risk containment on projects. As the study reveals, poor project governance has led to poor project management and procurement practices, inhibiting the implementation of good management of geotechnical risk necessary to minimize financial risks due to the inherently adverse ground conditions at project sites. The combination of these negative vices has created a propensity for extreme cost overruns on the highway projects, considering the wetland geologic setting of the Niger Delta. The study outcome has thus provided empirical evidence showcasing the contribution of mismanaged geotechnical risks to cost overruns experienced on highway project delivery in the Niger Delta.

The study further demonstrates the relevance of context to the argument on cost overruns, in public infrastructure projects, uncovering a wide array of social constructs, concomitantly at play in the highway project based organisations-which would have been overlooked in typically reductionist positivist studies. The robustness of the study findings has thus illustrated how adding contextual exploration of the cost overrun problem beyond mere statistics can add depth and richness to understanding the complex web of issues driving cost overruns in infrastructure projects. Cost overrun explanations therefore, should take into consideration the process and context- simplistic generalisations from statistical analysis only, would likely not yield a holistic understanding of the problem. The broader theoretical implication of this therefore lies in advancing the following nexus: the phenomenon of cost overrun in infrastructure projects should be numerically as well as contextually anchored.

The underlying drivers to cost overruns in projects, therefore cannot be properly understood if divorced from the organizational and project environment in which it occurred. As observed in this study, investigation into the impact of the precise impact of geotechnical risk upon costs, which ultimately should be the starting point for managing the risks involved, requires that the investigation has to travel back up through, and deal with the contextual and governance factors at the upper levels that are causing the problems lower down. The policy implication being the need for relevant institutional authorities to maintain a conducive organizational platform in highway agencies that gives adherence to best practise a priority. It is thus recommended that tackling cost overruns in highway projects requires concerted and specifically targeted efforts, aimed at curbing the intrinsic contextual triggers within and external to highway organisations.

\section{References}

Abam, T. K. S., Osadebe, C. C and Omange, G. N. (2005). Influence of geology on pavement performance: A case study of Shagamu-Benin City Road, southwestern Nigeria. Global Journal of Geological Sciences, 3 (1), 17-24.

Ahiaga-Dagbui D.D., Smith S.D., Love P.E.D and Ackermann, F. (2015). Spotlight on construction cost overrun research: superficial, replicative and stagnated, In Proceedings of the 31st Annual ARCOM Conference, 7-9th Sept, Lincoln, UK

Ahiaga-Dagbui, D. D and Smith, S.D. (2014). Rethinking construction cost overruns: cognition, learning and estimation. Journal of Financial Management of Property and Construction, 19(1), 38 - 54

Aibinu, A.A. and Odeyinka, A. (2006). Construction delays and their causative factors in Nigeria. Journal of Construction Engineering Management, ASCE, (132) 7, 667-677.

Aigbedion, I. (2007). Geophysical investigation of road failure using electromagnetic profiles along Opoji, Uwenlenbo and Illeh in Ekpoma-Nigeria. Middle-East Journal of scientific Research, 2 (3-4).111-115. 
Akoa, B.B. (2011). Cost Overruns and Time Delays in Highway Projects - Experiences from Cameroon. An unpublished Master's thesis submitted to Michigan State University

Alavi, S.A. and Tavares, P.E. (2009). Highway project cost estimating and management. The State of Montana Department of Transportation.

Allahaim, F. D and Liu, L. (2011). Understanding Major Causes Cost Overrun for Infrastructure Projects; A Typology Approach. Annual Conference of the Australasian Universities Building Educators Association (AUBEA)The University of New South Wales, Australia

An, S., Kim, G, and Kang, K. (2007). A case-based reasoning cost estimating model using experience by analytic hierarchy process. Journal of Building and Environment. 42(7), 2573-2579.

Attala, M., and Hegazy, T. (2003). Predicting Cost Deviation in Reconstruction Projects: Artificial Neural Networks Versus Regression. Journal of Construction Engineering and Management, 129 (4), 405-411.

Bea, R. (2006). Reliability and human factors in geotechnical engineering. Journal of Geotechnical and Geo-Environmental Engineering, May 2006, pp. 631-643.

Brandt, H. (2004). The Civil and Geotechnical Engineer in Society: Ethical and Philosophical Thoughts, Challenges and Recommendations. The Deep Foundations Institute, Hawthorne

Brunes, F and Lind, H. (2014). Explaining cost overruns in infrastructural projects: A new framework with applications to Sweden. Working Paper 01 Section for Building and Real Estate Economics, School of Architecture and the Built Environment, Royal Institute of Technology

Cantarelli, C. C., Molin, E. J. E., van Wee, B., and Flyvbjerg, B. (2012). Characteristics of cost overruns for Dutch transport infrastructure projects and the importance of the decision to build and project phases. Transport Policy, 22: 49-56.

Cantarelli, C.C., Flyvbjerg, B., Molin, E.J.E and Van Wee, B. (2010). Cost Overruns in Largescale Transportation Infrastructure Projects: Explanations and Their Theoretical Embeddedness. EJTIR 10(1), March, 5-18.

Chang, A. Shing-Tao. (2002). 'Reasons for cost and schedule increase for engineering design projects'. Journal of Management Engineering, ASCE, 18(1), 29-36.

Chou, J. (2005). Item-level quantity-based preliminary cost estimating system for highways, Doctoral dissertation presented to the faculty of the graduate school of the University of Texas at Austin.

Creedy. G.D. (2006). Risk Factors leading to cost overruns in the delivery of highway construction projects. An unpublished PHD thesis submitted to the Queensland University of Technology.

Cresswell, J.W. (2003). Research Design: Qualitative, Quantitative and Mixed Methods Approaches. 2nd ed. Thousand oaks, CA; Sage

Crowley, L and Hancher, D. (1995). Risk assessment of competitive procurement. Journal of Construction Engineering and Management, 121, 241-248.

Dainty, A.R.J. (2008) Methodological pluralism in construction management research. In Advanced methods in the Built Environment, A. Knight and L. Ruddock Eds, West Sussex, Wiley-Blackwell: 75-84

Department of the Environment, Transport and the Regions. (2014). Cost Overruns in Highway projects [online]. Available at $<$ nationalarchives.gov.uk $>$ accessed 13/06/15

Dlakwa M. M. and Culpin, M. F. (1990). Reasons for overrun in public sector construction projects in Nigeria. Lagos: Butterworth-Heinemann Ltd.

El-Kholy, A. M. (2015). Predicting Cost Overrun in Construction Projects. International Journal of Construction Engineering and Management. 4(4), 95-105.

Emujakporue, O. G. (2012). Geophysical investigation of the causes of highway failures in Niger Delta sedimentary basin (A Case Study of the Eastern part of East- West Road), Nigeria. Scientia Africana, 11 (1).143-152

European Union. (2011). Infrastructure Development: Abandoned, Incomplete and Substandard Projects Sponsored by Federal, State, and Local Governments; Oil Companies and 
International Organizations since 2000. Report on Public Services, Good Governance and Development in Niger Delta Communities

Flyvbjerg, B., Garbuio, M and D. Lovall. (2009). "Delusion and deception in large infrastructure projects: Two models for explaining and preventing executive disaster," California Management Review, 51(2) 170-193,

Flyvbjerg, B., Skamris Holm, M.K. and Buhl, S.L. (2002). 'Underestimating cost in public works. Error or Lie?', Journal of the American Planning Association, 68(3), 279-295.

Flyvbjerg, B., Skamris Holm, M.K., and Buhl, S.L. (2004). 'What Causes Cost Overrun in Transport. Fourth Transportation Specialty Conference of the Canadian Society for Civil Engineering Montréal, Québec, Canada

Gransberg, D.D and Gad, G.M. (2014). Geotechnical Requirements in Design-Build Selection Process. Paper presented at the Transportation Research Board (TRB) National Academies Annual Meeting, Washington.

Hinze, J and Gregory, S. (1991). Analysis of WSDOT Construction Cost Overruns. United States Department of Transportation, Federal Highway Administration. Report No. WA-RD 218.1.

Ihuah, P. W and Benebo, A. M. (2014). An assessment of the causes and effects of abandonment of Development projects on real property values in Nigeria. International Journal of Research in Applied, Natural and Social Sciences. 2(5), 25-36.

Institution of Civil Engineers. (1999). Inadequate site and ground investigations leading to construction delays and additional costs. Thomas Telford.

Institution of Civil Engineers. (2001). Managing geotechnical risk: improving productivity in UK building and construction, Thomas Telford.

Kaliba, C., Muya, M. and Mumba, K. (2008). Cost escalation and schedule delays in road construction in Zambia. International Journal of Project Management, 27(5), 522-531.

Lee, K and Kim, K. (2015). Collar Option Model for Managing the Cost Overrun Caused by Change Orders. [online]. Available at www.mdpi.com/journal/sustainability accessed $13 / 01 / 2016$.

Love, P.E.D. (2015). Understanding the Landscape of Overruns in Transport Infrastructure Projects. Environment and Planning and Design, 42, 490-509.

Love, P.E.D., Edwards, D.J, and Irani, Z. (2012) Moving Beyond Optimism Bias and Strategic Misrepresentation: An Explanation for Social Infrastructure Overruns. IEEE Transactions on Engineering Management 59(4):560-571

Love, P.E.D., Sing, C., Carey, B and Kim, J. (2013). Projects Estimating Construction Contingency: Accommodating the Potential for Cost Overruns in Road Construction. Infrastructure and Systems, 21(2).

Mansfield, N.R., Ugwu, O.O. and Doranl, T. (1994). Causes of delay and cost overruns in Nigerian construction projects. International Journal of Project Management, 12(4), 254-260.

Memon, A. H and Rahman, I. A. (2013). Analysis of Cost Overrun Factors for Small Scale Construction Projects in Malaysia Using PLS-SEM Method. Modern Applied Science; 7(8), 74-88.

Memon, A., Abdul Rahman, I., and Abdul Aziz, A. (2011), Preliminary Study on Causative Factors Leading to construction Cost Overrun. International journal of Sustainable Construction Engineering and Technology, 2 (1), 57-71.

Miles and Huberman's (1994) Miles and Huberman: Qualitative Data Analysis: An Expanded Sourcebook. London: Sage

Miles, M.B and Huberman, M. (1994). Qualitative Data Analysis: An Expanded Sourcebook. Sage.

Molenaar, K.R., Diekmann, K.E. and Ashley, D.B. (2006). A Guide to Risk Assessment and Allocation. for Highway Construction Management, Federal Highway Administration, U.S.

Morris, S. (1990). "Cost and Time Overruns in Public Sector Projects". Economic and Political Weekly, 47,154 to 168. Indian Institute of Management, Ahmedabad 
National Economic Development Office. (1988). Faster building for commerce. NEDO, London,

NDES. (1997). Environmental and Socio Economic Characteristics of the Niger Delta Region. Niger Delta Environmental Survey Report.

Ngerebara, O.D., Abam T. K. S and Nelson K. (2014). Geotechnical soil characterization of Akanfa-Gbaran Road, Bayelsa State, Nigeria. International Journal of Scientific and Research Publications, 4(4), 22-31.

Odeck, J. (2004). "Cost overruns in road construction: What are their sizes and determinants?" Journal of Transport Policy (11)43-53.

Oguara, T. M. (2002). Sustainable Development of High Infrastructure in the Niger Delta Region. Proceedings of the Nigerian Society of Engineers (NSE) Conference. 4-10.

Okon, U.M. (2009). NDDC's Approach to Infrastructure and Socio-Economic Development of the Niger Delta Region of Nigeria A master's thesis report submitted to the Faculty of Engineering and the Built Environment, University of the Witwatersrand, Johannesburg.

Okpala, D.C. and Aniekwu, A.N. (1998). Cause of high cost of construction in Nigeria. Journal of Construction Engineering and Management, ASCE, 114 (2) 223-34.

Ossai, S.U. (2012). Nigeria: The Challenge of abandoned Projects in the Niger Delta. Journal of Public policy and Development, 2(3), 34-45.

Otoko, G and Pedro, P. (2014) Cement Stabilization of Laterite and Chikoko Soils Using Waste Rubber Fibre. International Journal of Engineering Sciences and Research Technology,130- 136

PPAC. (2012). Report on NDDC projects. Presidential Projects Assessment Committee.

Reilly, J.J, McBride, M., Dye, D. and Mansfield, C. (1994). Guideline procedure "Cost Estimate Validation Process (CEVP)", Washington State Department of Transportation.

Romero, V. S. and J. M. Stolz, (2009). Cost Estimating for Underground Transit: Too Dangerous to "Guesstimate". San Francisco, CA

Sharma, S and Goyal, P, D. (2014). Cost Overrun Assessment Model in Fuzzy Environment. American Journal of Engineering Research, 3(7), 44-53.

Sowers, G.F. (1993). Human factors in civil and geotechnical engineering failures. Journal of Geotechnical Engineering. 119 (2), pp. 238-256.

Staveren, V and Meer, V. (2007). Educating geotechnical risk management. Proc. 1st Int. Symposium on Geotechnical Safety and Risk. Shanghai, China, 18-19 October.

Sunjka, B.P. and Jacob, U. (2013). Significant causes and effects of project delays in the Niger Delta region, Nigeria. SAIIE25 Proceedings, 9th - 11th of July 2013, Stellenbosch, South Africa. 641-649.

Teme, S.C. (2002). The physical environment, Engineering and water resources in Rivers state. Ministry of environment and water Resources (RSMEMR) Interim Guidelines and standards, $1-23$.

Transport and Road Research Laboratory. (1993). A guide to the structural design of bitumen surfaced roads in tropical and sub-tropical countries. Department of the Environment Department of Transport, Road Note 31.

Trost, S., M., and Oberlender, G., D. (2003). Predicting the Accuracy of Early Cost Estimates Using Factor Analysis and multivariate Regression. Journal of construction Engineering and Management, 129 (2), 198-204.

Turochy, R. E., Lester A. H., Lacy, L. A. and Robert S. D. (2001). Highway project cost estimating methods used in the planning stage of project development. Technical Assistance Report. Virginia Transportation Research Council.

Ubani, E.C. (2015). Analysis of Factors Responsible for Project Cost Underestimation in Nigeria. International Journal of Economics, Commerce and Management. 3(2), 1-12.

Ubani, E.C. and Ononuju, C.N. (2013). A study of failure and abandonment of public sectordriven civil engineering projects in Nigeria: An empirical review. American Journal of Scientific and Industrial Research.

Wachs, M. (1989). "When planners lie with numbers". Journal of the American Planning Association, 55, 476-479 
Wong, J. (2010). What lies Beneath? An Over View of Claims relating to unforeseen Ground Conditions. Institute of Civil Engineers.

World Bank (2000). Nigeria - Country Procurement Assessment Report (CPAR). Washington, DC: World Bank.

Yin, R. K. (2014). Case Study Research: Design and Methods (5th Ed.). Los Angeles: Sage Youdeowei P.O. and H.O. Nwankwala. (2013). "Suitability of soils as bearing media at a freshwater swamp terrain in the Niger Delta," Journal of Geologic Mineral Resource, 5(3) 58-64.

Youdeowei P.O. and H.O. Nwankwala. (2013). "Suitability of soils as bearing media at a freshwater swamp terrain in the Niger Delta," Journal of Geologic Mineral Resource, 5(3) 58-64. 